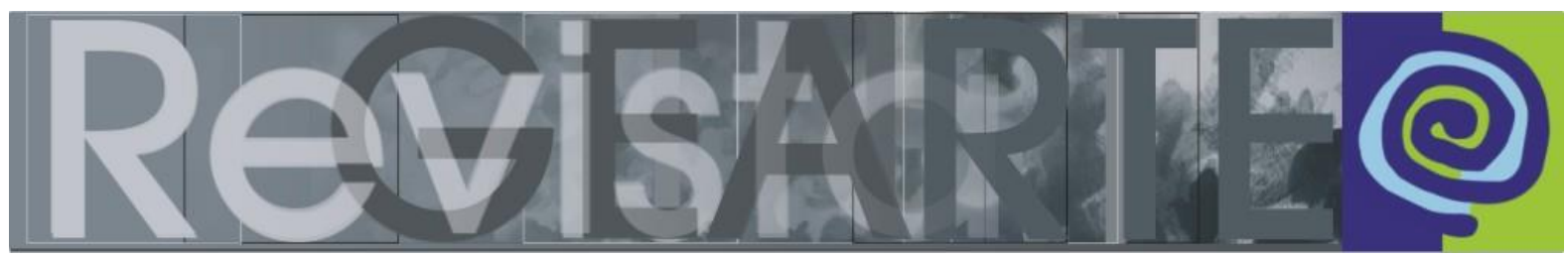

e-ISSN 2357-9854

\title{
Montulho Barricada (2017)
}

\author{
Patrícia Teles Sobreira de Souza (Universidade de \\ Brasília - UnB, Brasília/DF, Brasil)
}

\begin{abstract}
RESUMO - Montulho Barricada - O estudo apresenta o registro fotográfico da ação Montulho Barricada (2017) realizado no Campus Darcy Ribeiro da Universidade de Brasília, no âmbito da disciplina Tópicos em Poéticas Contemporâneas 2 - Poéticas da caminhada e do deslocamento (Programa de Pós-graduação em Arte) ministrada pela Profa. Dra. Nivalda Assunção. O trabalho consiste em ressignificar um amontoado de entulho por meio de sua redistribuição no espaço. Trasladar escombros, latas de tinta, pedaços de pau, blocos de concreto, entre outros resíduos, do ponto em que estavam depositados até o caminho entre o Restaurante Universitário e o Minhocão (UnB). O objetivo da ação é construir com o entulho uma barricada para 'des-automatizar' a passagem dos transeuntes. A produção da barreira visa provocar nos passantes uma tomada de decisão, seja ela a de atravessar, desviar ou de desmantelar o obstáculo.
\end{abstract}

PALAVRAS-CHAVE

Montulho. Barricada. Site-specific. Caminhada.

ABSTRACT - Montulho Barricada - The study presents the photographic record of the action Montulho Barricada (2017) held at the Darcy Ribeiro Campus of the University of Brasília, under the discipline Topics in Contemporary Poetics 2 - Poetics of walking and displacement (Postgraduate Program in Art) given by Profa. Dr. Nivalda Assunção. The work consists in re-signifying a heap of rubble through its redistribution in space. Transfer debris, paint cans, sticks, concrete blocks, among other residues, from the point where they were deposited to the path between the University Restaurant and the Minhocão (UnB). The purpose of the action is to build with the rubble a barricade to 'de-automate' the passage of the passers-by. The production of the barrier aims to provoke a taking decision, whether to cross, to divert or to dismantle the obstacle.

KEYWORDS

Montulho. Barricada. Site-specific. Walking.

\section{Montulho Barricada}

No meio do caminho tinha uma pedra

Carlos Drummond de Andrade

\#caminhada \#passagem \#trânsito \#caminho \#acesso \#percurso \#intransitável \#intransponível \#intrafegável \#bloco \#entulho \#sobra \#resíduo \#ruína \#resto \#escombro \#bloqueio \#barricada \#derrumbe \#barreira \#trincheira \#obstáculo \#obstrução \#contenção \#interrupção \#impedimento \#barragem \#represa \#entrave \#estorvo \#GOLPE 
Montulho Barricada consiste em ressignificar um amontoado de entulho por meio de sua redistribuição no espaço. Para este fim, escombros, latas de tinta, pedaços de pau, blocos de concreto, faixas, cadeiras quebradas, entre outros resíduos, foram trasladados do local onde foram jogados até o caminho entre o Restaurante Universitário e o Minhocão (Universidade de Brasília), trajeto de intensa circulação de passantes. Os objetos encontrados no campus da UnB foram depositados em um ponto estratégico, no qual o caminho torna-se mais estreito e rodeado por arbustos.

O entulho foi utilizado na construção de uma 'barricada' com a finalidade de des-automatizar a passagem dos transeuntes, desarticulando o movimento cotidiano de circulação dos corpos. A produção da barreira visa provocar nos passantes uma tomada de decisão, seja ela a de travessar, desviar ou de desmantelar o obstáculo. Desta forma, o trabalho reflete sobre a questão da caminhada a partir de duas instâncias: em um primeiro momento a caminhada se dá no ir e vir dos atuantes, no vai e vem dos corpos que carregam o entulho do espaço no qual foi depositado ao ponto onde será construída a barricada.

Por último, o estudo da caminhada reside na relação dos passantes com a estrutura armada. A maioria dos passantes optou por desviar-se do caminho habitual, seguindo o fluxo de pessoas que davam a volta pelo gramado do campus. Alguns transeuntes empurraram ou removiam - por vezes mais violentos, por vezes mais cuidadosos - parte da barricada para poder passar. Durante as duas horas de observação somente um senhor derrubou toda a estrutura.

Transladar os objetos descartados para uma localização de fluxo constante de pessoas implica um novo sentido para o entulho, este deixa de ser uma massa amorfa, cotidiana, encoberta, imperceptível e torna-se uma substância 'viva', notória, que desorienta os passantes. Portanto, o trabalho fundamenta-se na relação com os estudantes e funcionários que transitam no campus.

Montulho Barricada gera distintas leituras dos pedestres: uma estudante ficou apreensiva por acreditar tratar-se de uma greve; um senhor, que habita o campus, pensou ser uma provocação dos vigias que trabalham na Universidade e 
provavelmente o monitoram; alguns estudantes afirmavam, com deboche, que o montante de entulho era uma 'obra de arte'.

Ademais das interpretações divergentes promovidas pela redistribuição dos objetos no espaço, a barricada provoca uma redistribuição dos corpos, que saem do fluxo habitual de caminhada e necessitam atravessar outros espaços para chegar ao seu destino. Isto porque a estrutura se encontra no entremeio, apontado por Onfray (2009) como uma 'zona branca, neutra', entre o 'lugar deixado' e o 'lugar cobiçado'. O autor refere-se a longas distâncias, entretanto o termo é apropriado para pensar, não somente o entulho, mas o próprio caminho como algo ressignificado. Em outras palavras, com o deslocamento dos escombros, o entremeio deixa de ser uma zona branca e neutra e passa a ser um perímetro ativo.

\section{Referências}

ONFRAY, Michel. Teoria da viagem. Porto Alegre: L\&PM, 2009.

\section{Patricia Teles Sobreira de Souza}

Patrícia Teles é uma artista transdisciplinar, doutoranda em Arte (Universidade de Brasília), mestre em Lenguajes Artísticos Combinados (Universidad Nacional de las Artes), especialista em Arte, Cultura e Sociedade no Brasil (Universidade Veiga de Almeida) e bacharel em Artes Cênicas - Direção Teatral (Universidade Federal do Rio de Janeiro).

E-mail: patriciateles86@gmail.com

Currículo Lattes: http://lattes.cnpq.br/4329129306790870

Recebido em 19 de outubro de 2017 Aceito em 4 de maio de 2018 
Brasília, 11 de setembro de 2017.

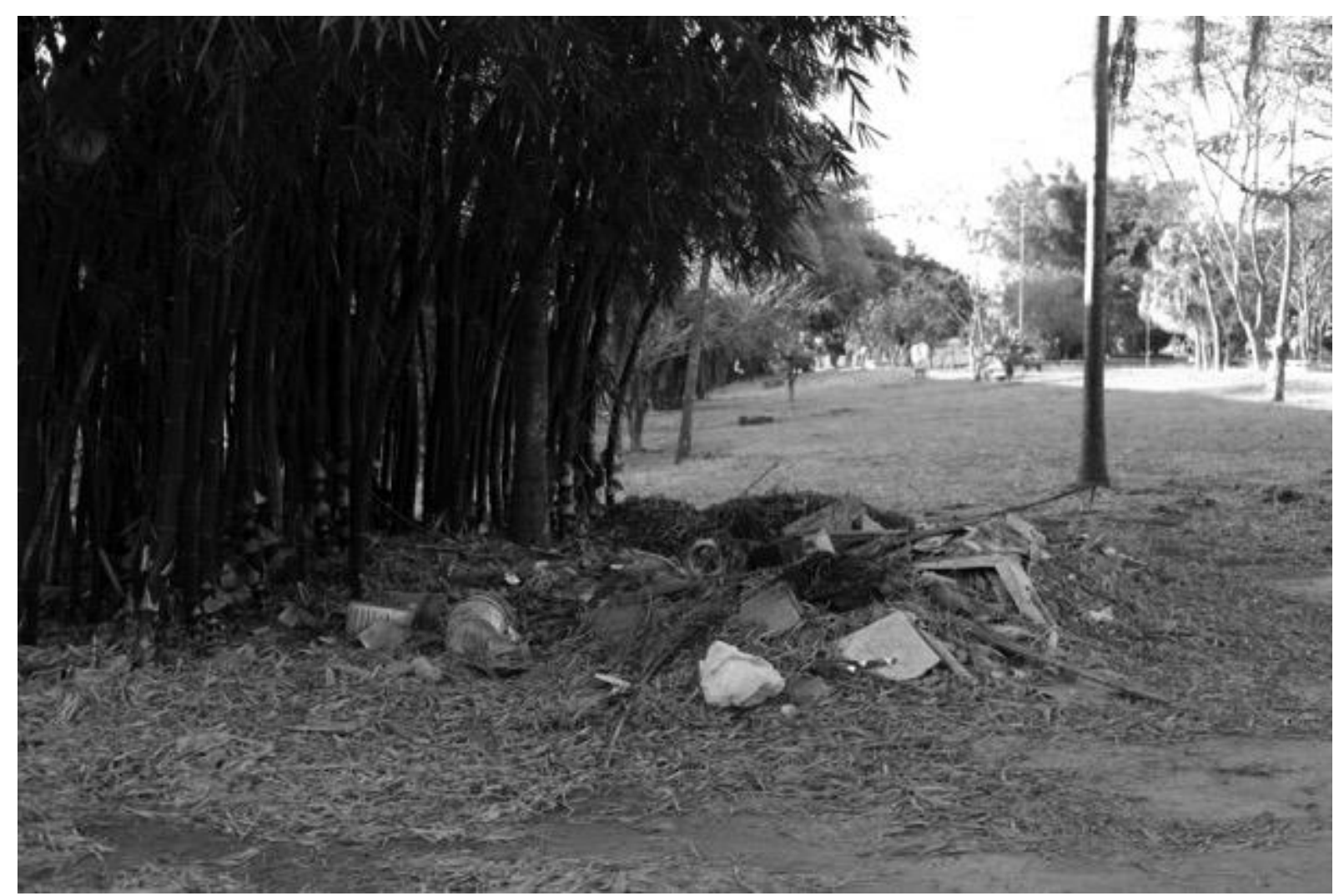

Entulho - Campus Universitário Darcy Ribeiro (UnB)

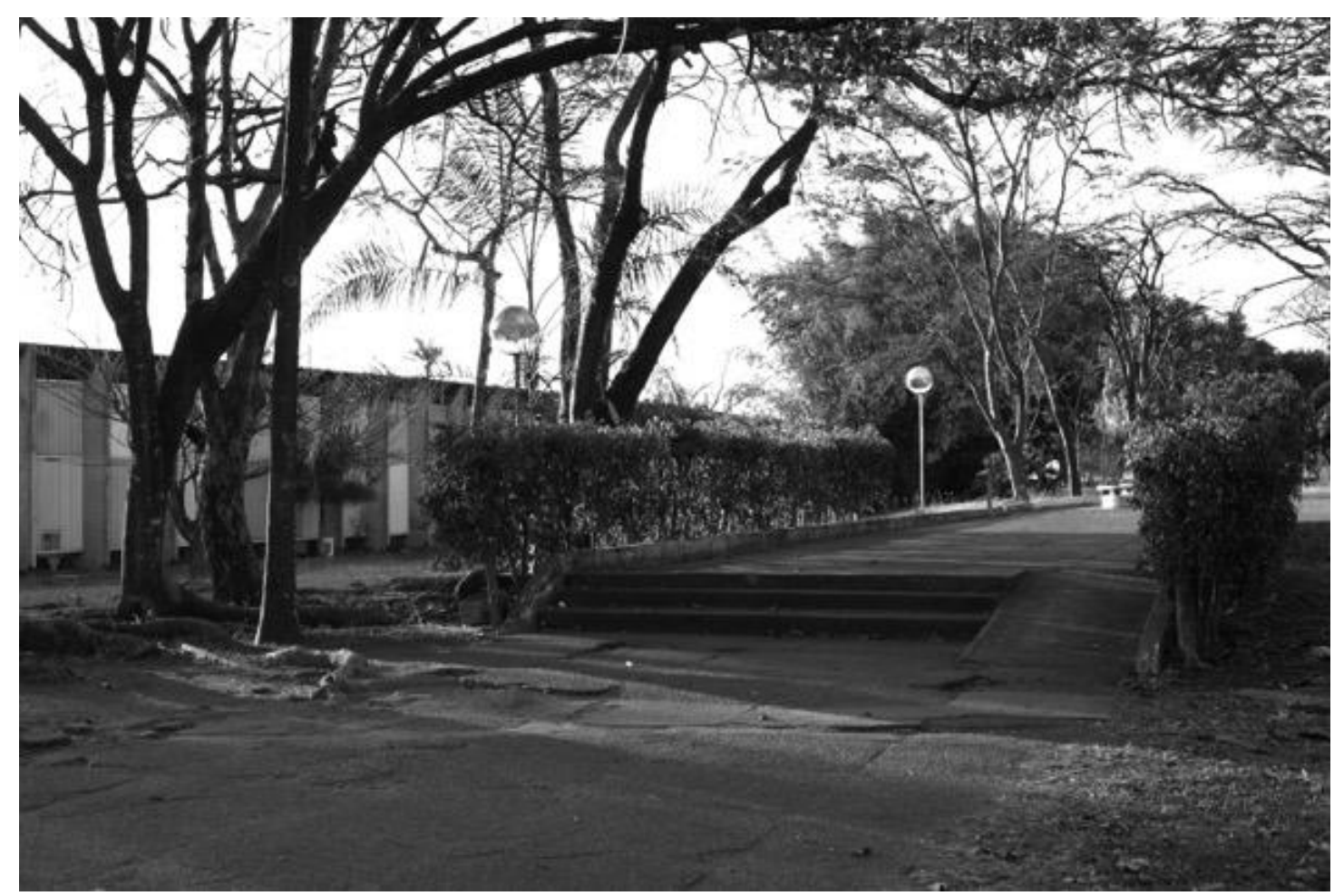

Caminho entre o Minhocão e o Restaurante Universitário (UnB) 

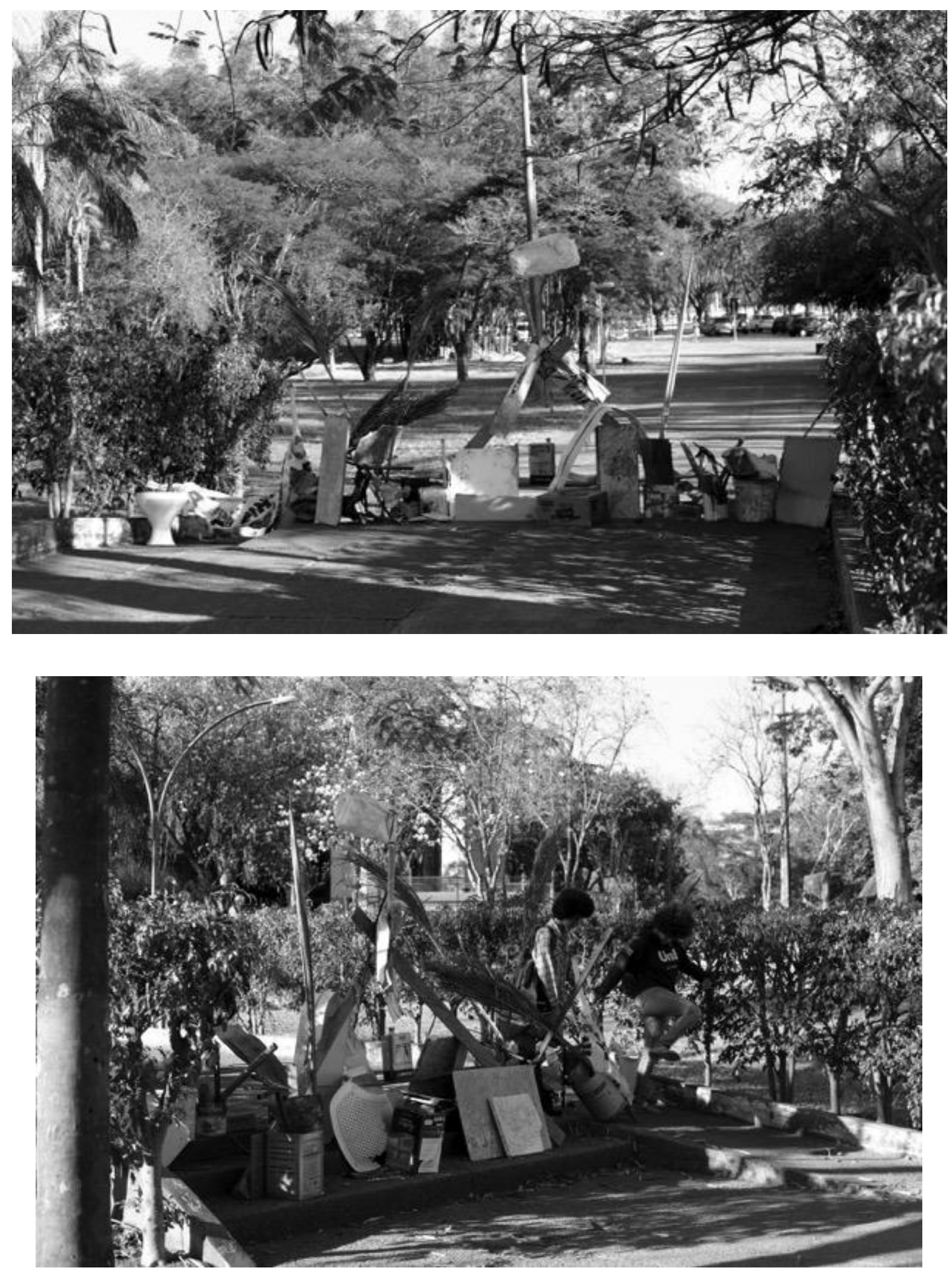

SOUZA, Patrícia Teles Sobreira de. Montulho Barricada (2017). 


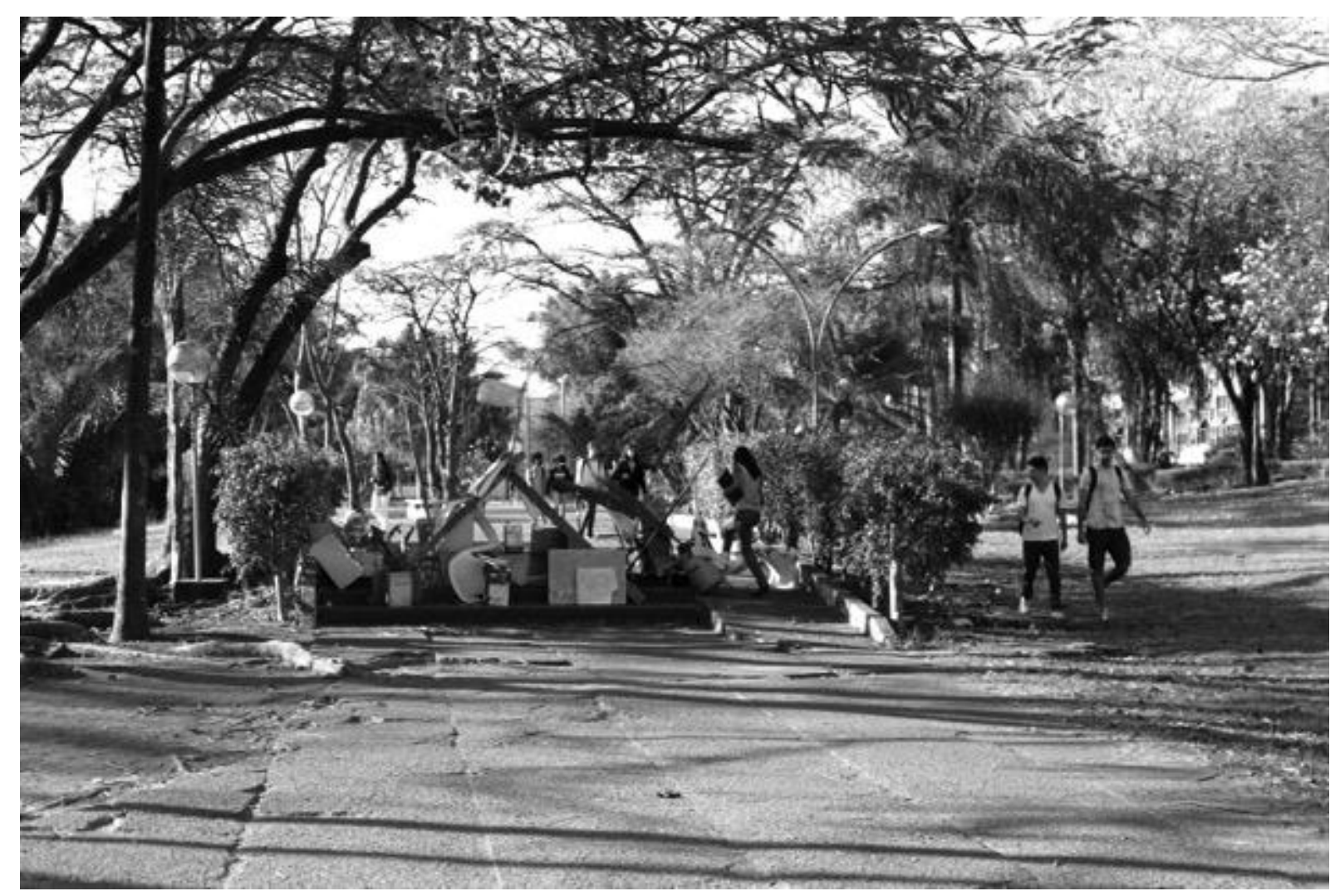

SOUZA, Patrícia Teles Sobreira de. Montulho Barricada (2017).

Revista GEARTE, Porto Alegre, v. 5, n. 2, p. 350-358, maio/ago. 2018.

Disponível em: http://seer.ufrgs.br/gearte 


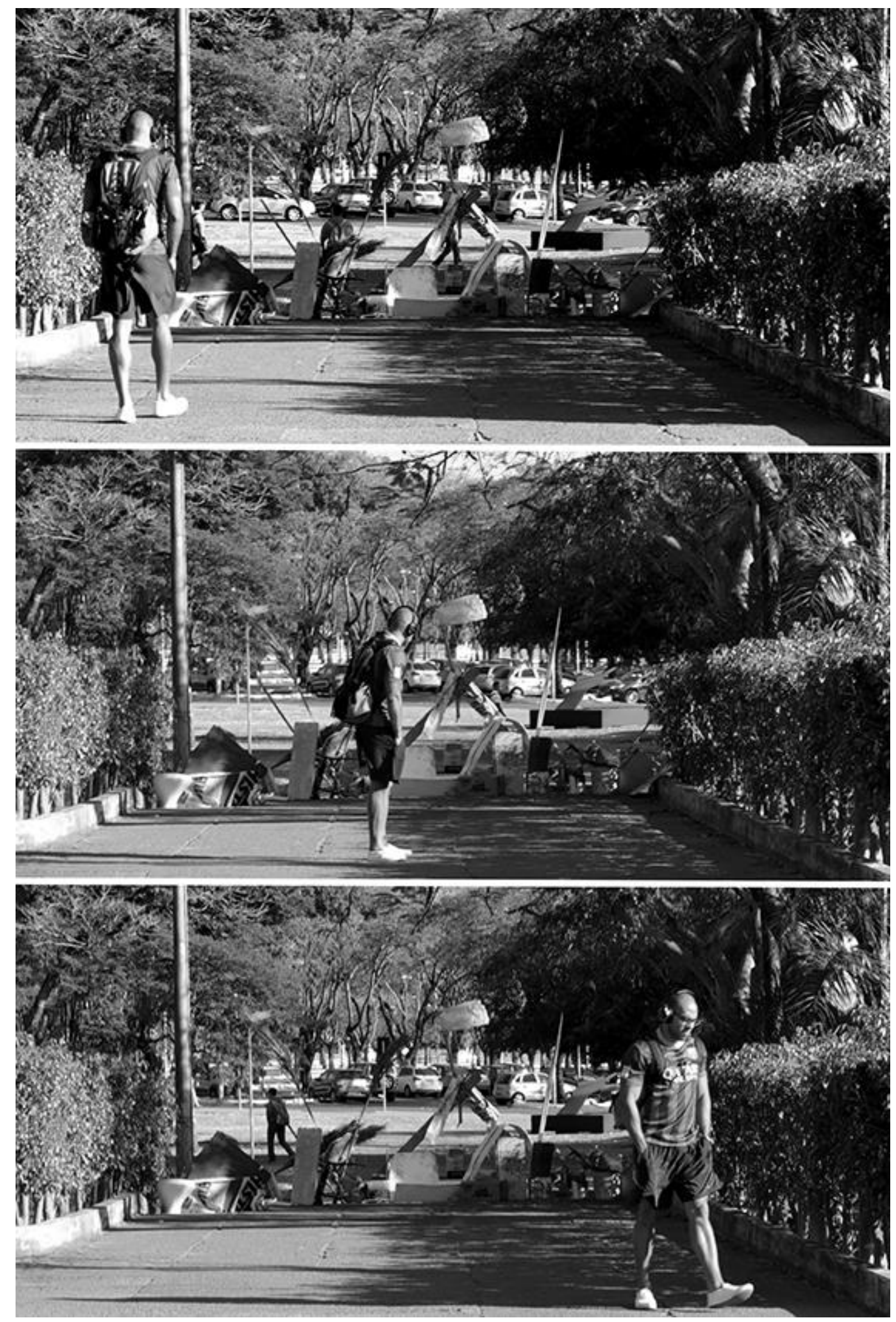

SOUZA, Patrícia Teles Sobreira de. Montulho Barricada (2017).

Revista GEARTE, Porto Alegre, v. 5, n. 2, p. 350-358, maio/ago. 2018.

Disponível em: http://seer.ufrgs.br/gearte 

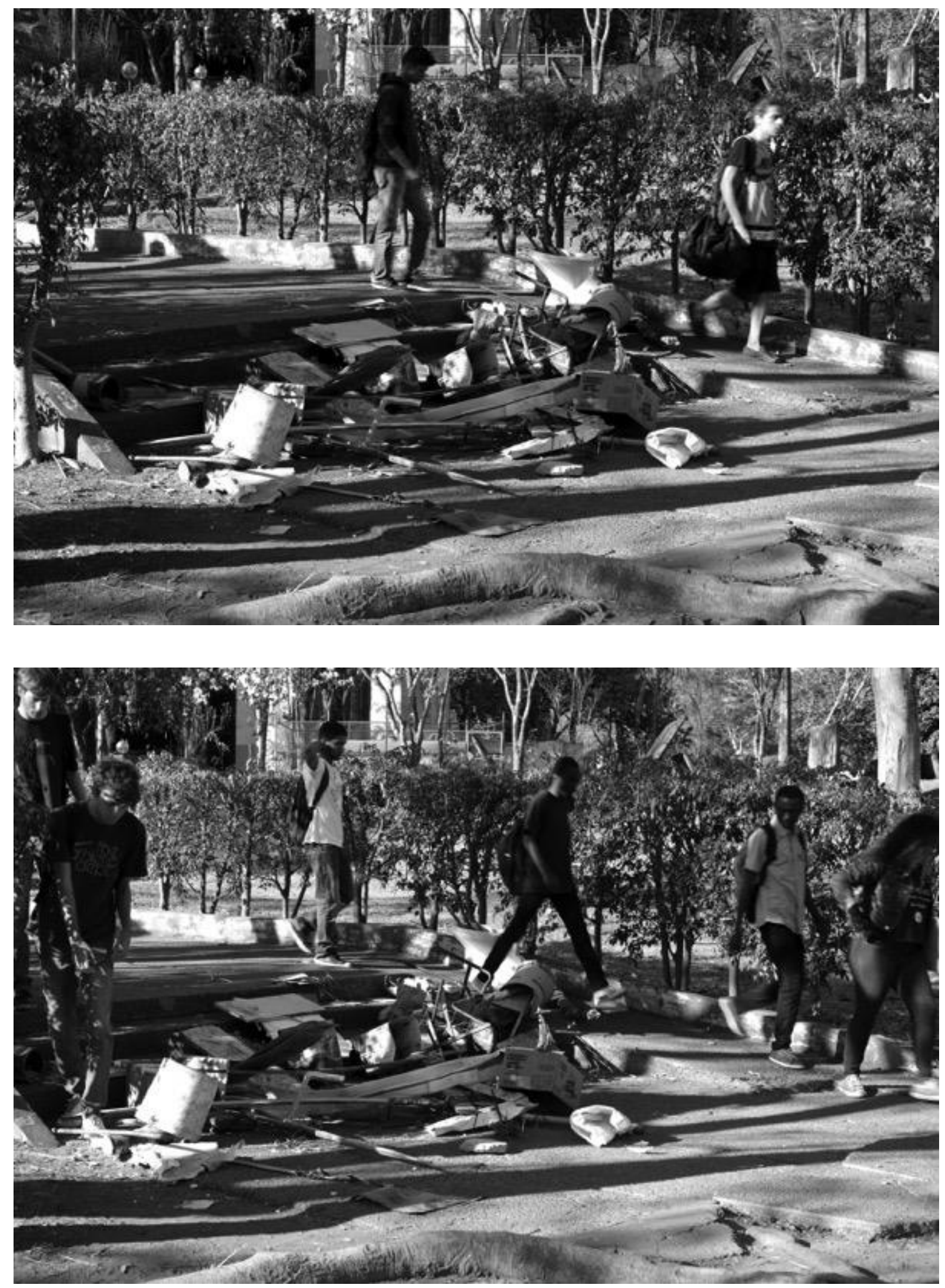

SOUZA, Patrícia Teles Sobreira de. Montulho Barricada (2017). 


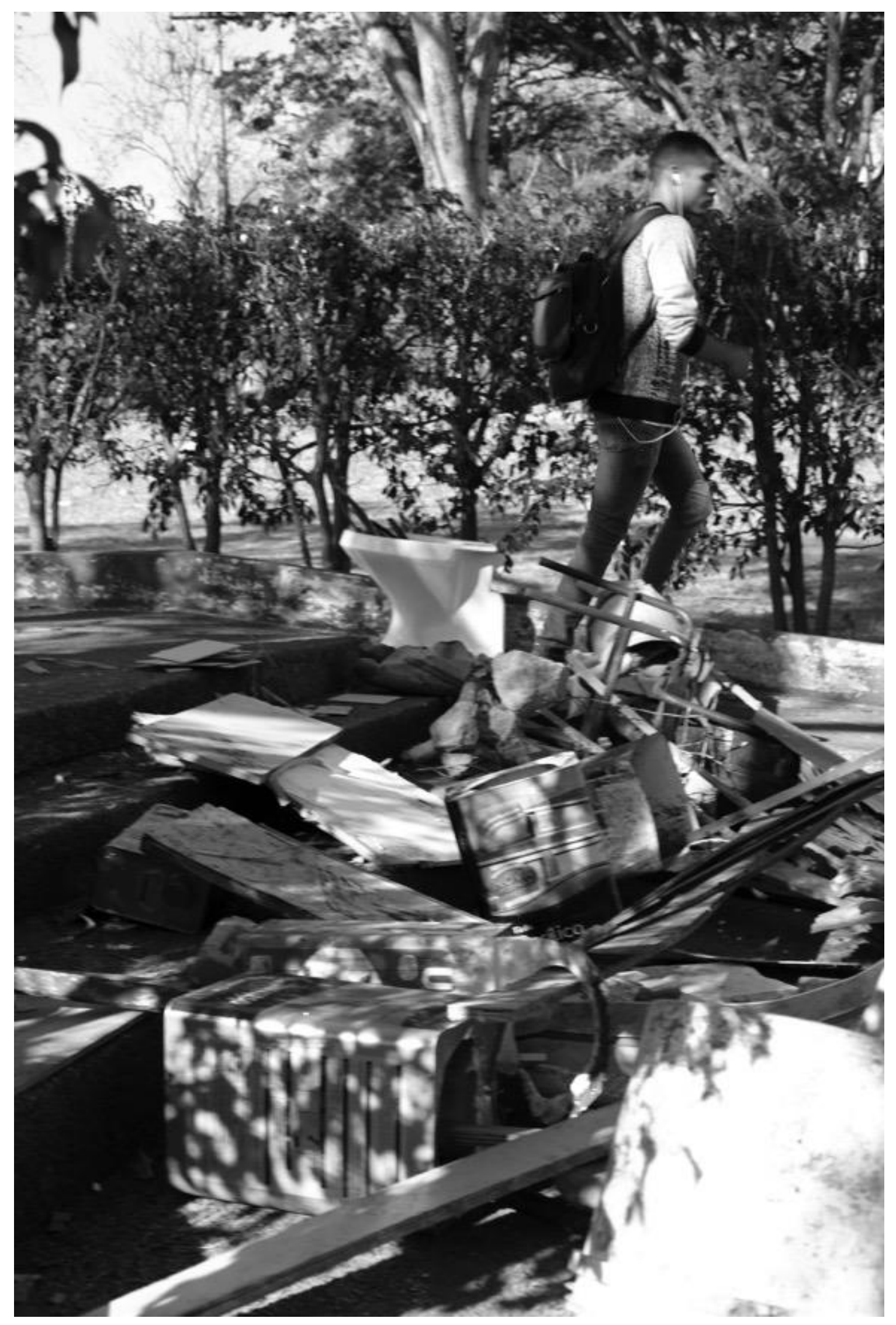

SOUZA, Patrícia Teles Sobreira de. Montulho Barricada (2017). 